\title{
Views of survivors of stroke on benefits of physiotherapy
}

\author{
Pandora Pound, Michael Bury, Patrick Gompertz, Shah Ebrahim
}

\begin{abstract}
Objective-To describe the components of physiotherapy valued by survivors of a stroke.

Design-Qualitative study using in-depth interviews.

Setting-Two adjacent districts in North East Thames Regional Health Authority. Patients-82 survivors of stroke taken consecutively from a stroke register when they reached the tenth month after their stroke, 40 of whom agreed to be interviewed.
\end{abstract}

Main measures-Content analysis of interviews.

Results-Patients who agreed to the interview were significantly less likely to be disabled 12 months after stroke than those who did not. Twenty four patients had received physiotherapy, and these were more disabled than those who had not. Patients appreciated physiotherapy. It was believed to bring about functional improvement; the exercise component was valued because it was perceived to keep them active and busy and exercise programmes to follow at home were also valued for the structure they gave to each day; and therapists were considered a source of advice and information and a source of faith and hope.

Conclusions-Many of the positive aspects of caring which patients described in the context of physiotherapy could be incorporated into the mainstream of rehabilitation care and training. However, health professionals need to be careful not to promote false expectations about recovery.

Implications-The outcome of treatment is of critical importance to patients and should become a central dimension of patient satisfaction questionnaires. The impact of physiotherapy is not confined to reducing physical disability but may also affect wellbeing. The choice of outcome measures in rehabilitation research should reflect this situation.

(Quality in Health Care 1994;3:69-74)

\section{Introduction}

Most people admitted to hospital with stroke receive physiotherapy, ${ }^{1}$ but a clear view on the impact of this treatment has not yet emerged. Several trials have attempted to determine the value of physiotherapy after stroke, but they are not easily comparable. ${ }^{2}{ }^{3}$ Trials are rarely randomised; settings are varied (for example, some study inpatient physiotherapy, some outpatient physiotherapy, and some domiciliary physiotherapy); and the content of the treatment is not standardised. ${ }^{+}$Moreover, outcome measures are not standardised and do not reflect the full range of rehabilitation aims or include assessments of patient and carer satisfaction. ${ }^{5}$ The most that can be drawn from these studies is that physiotherapy seems to be associated with modest improvements (according to functional and physical outcome measures) in the first few months after a stroke, ${ }^{36}$ although recent work suggests that there may also be benefits late after a stroke. $^{7}$

A previous study of ours disclosed that six months after their stroke $85 \%$ of people were satisfied with the rehabilitation they had had but that only $46 \%$ were satisfied that they had received enough rehabilitation. ${ }^{8}$ However, the study was unable to explain why the majority thought they needed more rehabilitation. Little is known about patients' attitudes towards rehabilitation, although Anderson gained the impression that patients valued therapists' interest and positive approach. ${ }^{1} \mathrm{He}$ also suggested that in the beginning therapists encourage high hopes of recovery, but that later on many patients become disappointed because this recovery has not been achieved. Anderson did not ask patients systematically about the service they received, but his insight offers a possible explanation for the results of our patient satisfaction survey.

This paper examines in greater depth the reasons why people thought they had not had enough rehabilitation. Explorations of this kind require the collection of data that are rich in information and these can often be obtained from a relatively small number of interviews. In depth, semistructured interviews seemed the most appropriate way of allowing people to talk freely about their experiences according to their own priorities. A qualitative method such as this is well suited to exploring the complexity of peoples' experience $^{910}$ and also has the potential to throw light on the social contexts in which patients evaluate their health care. Survivors of stroke may receive a combination of physiotherapy, occupational therapy, or speech therapy, depending on the type of stroke they had. However, for simplicity the analysis concentrates exclusively on physiotherapy since this is the most common form of rehabilitation after stroke. 


\section{Methods}

We wanted to gain a representative sample of people admitted to hospital with stroke, rather than structuring the sample to select only people who had experience of physiotherapy. During nine months, consecutive patients in the North East Thames stroke outcome study (NETSOS) stroke register (the same sampling frame used in the patient satisfaction survey), when they reached the tenth month after their stroke, were invited to take part in an interview. Those patients lost to follow up in the outcomes study during the nine month period, those who had moved out of the study area, those still inpatients at 10 months, and those known to be unable to participate in an in depth interview owing to dementia (three patients) or severe speech impairment (three) were excluded from the sampling frame. Additionally, because fewer women than men were able to participate in the interviews, mainly for reasons of ill health, men were excluded from sampling during the last two months. The register contains data on all acute stroke admissions to the four major hospitals in two adjacent health districts in North East Thames region between January 1991 and March 1992. In the outcomes study survivors were followed up at six and 12 months with a range of postally administered questionnaires, including the Nottingham Extended Activities of Daily Living (NEADL) scale, ${ }^{11}$ the Barthel activities of daily living index, ${ }^{12}$ the Nottingham health profile, ${ }^{13}$ the short form of the geriatric depression scale, ${ }^{14}$ and the patient satisfaction questionnaire. ${ }^{8}$

The differences between those who accepted and those who refused the invitation to participate in the in depth interviews were investigated with Student's $t$ test, the MannWhitney $U$ test, and Pearson's $\chi^{2}$, where appropriate.

The interviews were conducted an average of ten months after the strokes. All (except one) were conducted in peoples' homes and tape recorded, and all were conducted, transcribed, and analysed by PP. The interviewer used a guide (see box) to ensure that each conversation covered the same general areas, but within subject areas the conversation was flexible so that issues could be explored in more depth by tailoring subsequent questions to deal with each person's particular situation. ${ }^{15}$ The transcripts were subjected to content analysis, ${ }^{15}$ which entails reading through the data, identifying recurrent themes or themes which seem important to the interviewees, and organising them into categories. This type of analysis was used because as far as possible we wanted to present the interviewees' views rather than imposing our own. In the specific examples given below the names of the interviewees have been changed to preserve anonymity.

\section{Results}

SAMPLE POPULATION

Of the 82 patients invited to participate in an in depth interview, 40 accepted, a rate of $49 \%$. The sample comprised 21 men and 19

\section{Interview guide}

- Could you tell me what happened the day you had your stroke?

- What happened when you got into hospital?

- What do you think would have happened if you had not gone into hospital?

- How did the hospital help you? (if appropriate)

- Did you have any physiotherapy/speech therapy/occupational therapy while in hospital?

- What did you think of it (type of therapy)?

- Are you happy with the amount of therapy you have had?

- Is there any treatment you feel you should have had, that you were not offered?

- Thinking back to all the people you saw while you were in hospital which were the most useful to you? (Why was that?)

- You've been home for about 10 months. What would make the most improvement in your life now?

women; 35 were white, three were Bangladeshi, and two were black Caribbean. The mean age at the time of interview was 71.5 years (range $40-87$ years). Twenty three patients lived in council housing and five in warden supervised accommodation, eight were owner occupiers, two were living in privately rented houses, one in bed and breakfast accommodation and another was staying in her daughter's home at the time of the interview. Thirty nine patients identified a main carer, of whom 19 were spouses. Sixteen people lived alone.

There were no significant differences six months after the stroke between those who accepted the invitation to be interviewed and those who refused, either in terms of disability (with the Barthel index and the NEADL scale) or according to age at time of stroke, age left full time education, last employment (manual or non-manual), whether living alone, housing tenure, sex, or race. However, those who accepted were significantly less likely to be disabled 12 months after the stroke than those who refused (table). At the same time, however, the patients in the sample had a fairly high level and wide range of disability, as the scores indicate. The median Barthel score (range 0-20, 0 indicating greatest disability) for the sample was 17 , six months after the stroke and 16.5 at 12 months (table), indicating that patients were moderately dependent in basic activities of daily living such as self care, using the toilet, and mobility. For extended activities of daily living (with the NEADL scale (range 0 to 22,0 indicating greatest disability) the group scored a median of 8 at six months after the stroke and 9 at 12 months, suggesting the need for daily support from a carer or from social services. With the geriatric depression scale the sample scored a mean of 7 at both six and 12 months, indicating a fairly high level of depression. ${ }^{16}$ 
Comparison of survivors of stroke who accepted invitation to interview and who did not, according to outcomes at six months and 12 months

\begin{tabular}{|c|c|c|c|c|c|c|c|}
\hline & \multicolumn{2}{|c|}{ Six months } & \multirow[b]{2}{*}{ Significance } & & \multicolumn{2}{|c|}{12 months } & \multirow[b]{2}{*}{ Significance } \\
\hline & $\begin{array}{l}\text { Interviewed } \\
(n=40)\end{array}$ & $\begin{array}{l}\text { Not interviewed } \\
(n=41)\end{array}$ & & & $\begin{array}{l}\text { Interviewed } \\
(n=38)\end{array}$ & $\begin{array}{l}\text { Not interviewed } \\
(n=28)\end{array}$ & \\
\hline $\begin{array}{l}\text { Median score Barthel index } \\
\text { Median score NEADL scale } \\
\text { Nottingham health profile } \\
\text { mean scores: }\end{array}$ & $8^{\star}$ & $\begin{array}{r}16 \\
7\end{array}$ & $\begin{array}{l}0 \cdot 19 \\
0 \cdot 13\end{array}$ & $\begin{array}{l}\text { Median score Barthel index } \\
\text { Median score NEADL scale } \\
\text { Nottingham health profile } \\
\text { mean scores: }\end{array}$ & $\begin{array}{c}16 \cdot 5 \\
9\end{array}$ & $\begin{array}{l}13^{\star \star} \\
3 \cdot 5^{\star \star}\end{array}$ & $\begin{array}{l}0.039 \ddagger \\
0.014 \ddagger\end{array}$ \\
\hline $\begin{array}{l}\text { Energy } \\
\text { Pain } \\
\text { Emotion } \\
\text { Sleep } \\
\text { Social isolation } \\
\text { Physical mobility } \\
\text { Mean score geriatric } \\
\text { depression scale }\end{array}$ & $\begin{array}{r}56 \\
20 \\
7 \\
30 \\
21 \\
40 \\
7\end{array}$ & $\begin{array}{c}58 \\
28 \\
24 \\
35 \\
23 \\
45 \\
6^{\star}\end{array}$ & $\begin{array}{l}0.50 \\
0.19 \\
0.97 \\
0.67 \\
0.22 \\
0.19 \\
0.92\end{array}$ & $\begin{array}{l}\text { Energy } \\
\text { Pain } \\
\text { Emotion } \\
\text { Sleep } \\
\text { Social isolation } \\
\text { Physical mobility } \\
\text { Mean score geriatric } \\
\text { depression scale }\end{array}$ & $\begin{array}{r}56 \\
21 \\
28 \\
31 \\
27 \\
48 \\
7\end{array}$ & $\begin{array}{c}60 \\
35 \\
29 \\
36 \\
28 \\
54 \\
8 \dagger\end{array}$ & $\begin{array}{l}0.71 \\
0.06 \\
0.83 \\
0.51 \\
0.89 \\
0.47 \\
0.45\end{array}$ \\
\hline
\end{tabular}

$\star^{\star} \mathrm{n}=39$.

$\begin{aligned} & \star \star n \\ & \star \star n\end{aligned}=29$.

tn $=21$.

ISignificant.

Scores with the Nottingham health profile were similar to those in a comparable sample of stroke survivors ${ }^{17}$ and indicated that the main problems lay in energy and physical mobility.

Twenty four patients had received physiotherapy. According to average scores on the Barthel index and the NEADL scale, people who had had physiotherapy were more disabled than those who had not at six months (Barthel index: mean score $13 v 17$; NEADL scale: mean score $7 \quad v 13$ ) and 12 months (Barthel index: mean score $14 v 17$; NEADL scale: mean score $7 v 13$ ).

\section{Content analysis}

Nineteen patients were classified as being positive about physiotherapy (although some of them also suggested how aspects of the service could be improved), one as being negative, and four as being indifferent. The results presented are based on data from all 40 interviews but the main focus is on those 24 patients who had received physiotherapy. Four main themes emerged, each of which was expressed with sufficient frequency to suggest general importance to the whole sample. The number of patients contributing to each theme is included to give an indication of its relative importance.

\section{POSITIVE ATTITUDE}

Physiotherapy was appreciated for the following reasons. Firstly, it was believed to bring about functional improvement. Secondly, in the context of stroke the exercise component was valued because it was perceived to "keep you moving, keep you going, and keep you busy." Exercise programmes at home were also valued for the structure they gave to each day. Thirdly, therapists were a source of advice and information, and fourthly, they were a source of faith and hope.

\section{Functional improvement}

Over half those (13) who had physiotherapy believed that the treatment had brought about physical improvement and had been instrumental in their regaining the use of specific limbs or abilities. Many suggested that physiotherapy had been crucial to their recovery. Running through the interviews was a thread of commentary suggesting that because many people perceived physiotherapy to have brought about recovery in the first place they also believed that the more physiotherapy they had the more they would recover. Five people thought at this stage (10 months) that they could still benefit from further therapy. For example, one patient accompanied her husband to some of his physiotherapy sessions and felt that they were of great value to him. However, after a few sessions the treatment stopped, and she could not understand why her husband had still not regained the use of his hand.

\section{Exercise}

Half the people (12) who had had physiotherapy appreciated it because of the exercise component of the treatment. Exercise was automatically taken to be positive and beneficial but over and above that it seemed to acquire particular meaning in the context of stroke. People often described their limbs as lifeless, dead, heavy, or numb, and there was a suggestion that without exercise the paralysis would somehow "set in," or the body would "seize up." The value of exercise to this sample seemed to be expressed in three central themes: it keeps you moving, keeps you going, and keeps you busy.

Example- $\mathrm{Mr}$ Higgins, demonstrating his exercises to PP commented that they helped to keep his "old bones" moving, as well as the muscles in his leg. While some people might let themselves go as they got older, he suggested that by exercising he was making a positive commitment to staying healthy. Additionally the exercises kept him busy. Whereas some people might sit down and do nothing, he knew that each day he had a set routine of exercises to perform.

He was not alone in placing a high value on a programme of exercises to carry out at home. Such programmes were tailored to peoples' individual needs and abilities, meaning that everyone was able to do something whatever their circumstances.

\section{Advice and information}

Eight people referred to physiotherapists as valuable sources of advice and information about functional improvement and exercising. Most had obtained information on how to 
maximise recovery after discharge and wanted to make sure that they would not do things which might impede recovery or cause further damage. They had been advised about how to behave once they were at home - for example, how to stand up "correctly," how to avoid poor posture, or how to exercise their arms and legs. However not everybody received the advice they desired.

Example-Mr Weaver was confused about several things. He showed the way he transferred from his chair, but he was worried in case he was not doing it correctly. He used an electric massager on his weak leg and he felt that this "toned it up" temporarily, but he had been given no advice about exercising this leg. Furthermore, because one of his hands was still weak, he was wondering whether or not he should try and strengthen it by squeezing on a rubber ball.

Some people indicated that they would value feedback after discharge, in the form of home visits by physiotherapists. This was a service that few had experience of, but which would apparently be much appreciated. There also seemed to be a desire for information about prognosis and for regular reviews of progress. Many people set their own goals, such as striving to be able to walk with a frame by six months after the stroke, and they seemed to be asking for some form of evaluation of their progress.

\section{Faith and hope}

The accounts of seven patients suggested that physiotherapists were regarded as a source of faith or hope, or both. In those patients who had given up on their bodies, and perhaps who had lost the will to recover, physiotherapists were described as having restored faith.

Example-For six weeks after his stroke $\mathrm{Mr}$ McCarthy lay in bed, resigning himself to the fact that he would never use his legs again, until a physiotherapist visited him and told him he could walk. Mr McCarthy described the event in terms of a miracle; he could barely believe that he was on his feet again, saying that he had "felt like Jesus walking on water."

For those who already had the determination and will to get better, physiotherapists seemed to be drawn on as a resource to help them in their struggle to recover.

Example-Mrs Patten, although determined enough to start the difficult task of walking with her frame, considerably appreciated the encouragement of her physiotherapist in doing this and also in trying to start writing again, which she was more doubtful about. However, by the time she returned home Mrs Patten was pleased to have been able to sign and send out all her Easter cards herself.

NEGATIVE ATTITUDE

Only one person was negative about physiotherapy, because of the pain she endured as a result of being encouraged to stand up.

INDIFFERENT ATTITUDE

The main reason why four patients were indifferent towards physiotherapy was because they were already able to carry out activities that were important to them and considered that the treatment had nothing more to offer.

Example-When Mrs Samuels was asked whether she thought more physiotherapy would be beneficial, her husband replied that it did not really matter because she could now manage to get to the toilet on her own. Mrs Jacobs felt she could already walk satisfactorily, and $\mathrm{Mr}$ White thought his best treatment was to go out walking with his dog.

\section{PATIENTS WITHOUT EXPERIENCE OF} PHYSIOTHERAPY

Most of the patients who did not have physiotherapy did not express a wish that they had had it and most did not seem to have needed it. However, one patient who had had only an initial assessment was told that he did not need physiotherapy because the "feeling and actions" would come back naturally. This was not the case and he felt that if he had had some therapy he would not be experiencing the problems he still had with his arm and left leg. Another patient had contacted the hospital several times in an attempt to arrange physiotherapy for her mother because she thought it would help to ease her pain. Ultimately the patient did her own exercises at home but seemed to feel a need for professional advice as to whether she was doing them properly.

\section{Discussion}

RESPONSE RATE

The main reasons given for non-participation were the effects of ill health, which is not surprising, given the population studied. Many of those who refused may have done so because they had already contributed a great deal to the outcomes study. Consideration of the demands on people in the main study was also a reason why non-responders were not followed up. However, despite the low take up rate for the interviews, those patients who accepted were no different from those who refused, with the exception of being slightly less disabled at 12 months. The interview group were therefore probably slightly less disabled than a sample of all survivors would have been, but their level and range of disability were still fairly high, as the median scores with the Barthel index and NEADL scale indicate. The relatively low proportion of people who received physiotherapy probably reflects this slightly lower level of disability and the fact that the study was of survivors and of those living at home.

PATIENTS' VIEWS OF PHYSIOTHERAPY AND IMPLICATIONS FOR PRACTICE

First and foremost physiotherapy seemed to be valued among this group of patients because it was believed to be crucial to the recovery of functional ability. Patients believed that the more therapy they had the more complete their recovery would be. Whether this is true clinically remains to be determined. A 
problem is that in this atmosphere of uncertainty patients may foster unrealistic hopes about the potential of physiotherapy.

Though maintaining hope is often vitally important, Hoffman argued that hospital staff unconsciously promote an extended belief in recovery through various communication strategies (for example, being vague about prognosis) in order to deal with their own feelings that "nothing can be done" for people who have had a stroke. ${ }^{18}$ Davis, in an earlier study, noted the issue of maintaining "functional uncertainty" in managing chronic illness. ${ }^{19}$ However, problems arise when therapy ends. ${ }^{20}$ Patients may feel abandoned: they are left to deal with the recognition of their disability and to begin the lonely and painful task of adjusting to it. Maintaining and promoting "faith and hope" therefore needs to be balanced against the reality of the disability that stroke entails, although achieving this balance is not easy.

Though patients are concerned with the outcome of their treatment, this study suggests that they also gain a great deal from its process, as illustrated by their appreciation of exercise. Exercise has positive connotations generally, but it may take on particular meaning for survivors of stroke owing to the nature of stroke itself. Stroke is a condition synonymous with paralysis and inactivity, but exercise implies movement and animation. The treatment itself is active and physical. The patient often works together with the professional instead of being passive and acted upon. In this context then, the idea that exercise keeps you moving has important symbolic value.

The belief that exercise "keeps you going" is perhaps specific to old age. Some people may welcome old age, others may surrender to it, but many, as Williams points out, ${ }^{21}$ feel it should be resisted. The moral component of the latter may be expressed through the idea that others are wrong if they are "just sitting around waiting to die." 21 By engaging in exercise and remaining active in the face of illness the negative features and stereotypes attached to old age may be resisted. In emphasising the value of exercise, patients and their carers may also be expressing the need to be seen in a positive light, in comparison with others who have "given up." Thus exercise and activity may simultaneously be an expression of a continuing engagement in life, and of social distance.

Patients appreciated exercise for "keeping busy" when the had been given a programme of exercise to follow at home. After a stroke a person may lose their physical independence, their autonomy, and they be unable to fulfil previously valued roles. The threat of "rolelessness" constitutes one of the main challenges of old age in modern societies ${ }^{22}$ and is reinforced by the aftermath of a condition such as stroke. In this context then, the knowledge that a certain number of exercises needs to be done every day may provide a partial substitute for lost roles and lend a valuable structure to the day.
Clinical, nursing, and rehabilitation staff might benefit from a deeper understanding and appreciation of the meaning of stroke and from a greater sensitivity to the particular experience which stroke entails. Perhaps because of a preoccupation with the clinical aspects of stroke, especially with neurological and functional outcomes, health professionals have failed to recognise the importance, and in some cases the symbolic value, of the different aspects of caring which stroke survivors have drawn attention to here in the context of physiotherapy. Many of the positive aspects of physiotherapy which patients described could well be incorporated into mainstream rehabilitation care and training.

IMPLICATIONS FOR RESEARCH

For these patients the primary concern seemed to be with the outcome of treatment, in tems of physical recovery. However in research of patient satisfaction people are less commonly asked for their views on the outcome of their treatment and what it means to them than they are for their views on the hotel aspects of health care or the personal qualities of staff. ${ }^{23-25}$ Within rehabilitation research too there is a popular myth that people enjoy physiotherapy simply because physiotherapists are "nice people." However this study suggests that the personal qualities of therapists are of less importance to patients compared with their main priority, which is to get as much treatment as possible and to get better.

Our findings also have implications for rehabilitation research. These patients indicated that they gained important benefits from their physiotherapy in addition to the recovery of physical function, suggesting that the choice of outcome measures traditionally used in rehabilitation research may have been lacking in content validity. Measures have focused almost exclusively on functional outcomes and have failed to reflect the other benefits which may be gained from physiotherapy, such as an increased feeling of wellbeing or a sense of self-worth.

Qualitative research has an important place in evaluating health care. It is capable of providing insights into patients' priorities and predicaments, which should bring about not only more sensitive care but also a deeper understanding of the way in which patients make their evaluations of health care. Patient satisfaction measures are still relatively crude instruments and, although they are able to indicate general areas needing attention, they are often unable to give the depth of understanding required to bring about sensitive change.

Our findings were generated from a small number of interviews with a relatively mildly disabled group of stroke survivors. The intention is that they should stimulate debate about the process of rehabilitation rather than that they should be generalised. Ultimately, the ideas formulated here should be further explored in a larger sample of stroke patients being cared for both in hospital and in the community with both qualitative and quantitative forms of assessment. 
We acknowledge funding from the Stroke Association, the Research Unit of the Royal College of Physicians of London, North East Thames Regional Health Authority's locally organised research scheme, and the generosity of all the people we interviewed.

1 Anderson R. The aftermath of stroke. Cambridge: Cambridge University Press, 1992

2 Effective Health Care. Stroke Rehabilitation. Leeds: University of Leeds, 1992. (Bulletin No 2)

Ebrahim S. The clinical epidemiology of stroke. Oxford Oxford Medical Publications, 1990

4 Tallis R. Rehabilitation of the elderly in the 21 st century. FR Coll Physicians Lond 1992;26:413-22.

5 Seale C, Davies P. Outcome measurement in stroke rehabilitation research Intemational Disability Studies 1987;9:155-60.

6 Freemantle N, Pollock C, Sheldon TA, Mason JM, Long $\mathrm{AF}$, Ibbotson S. Formal rehabilitation after stroke Quality in Health Care 1992;1:134-7.

7 Wade D, Collen MC, Robb GF, Warlow CP. Physiotherapy intervention late after stroke and mobility. BMY intervention late

8 Pound P, Gompertz P, Ebrahim S. Patients' satisfaction with stroke services. Clinical Rehabilitation 1994;8:7-17.

Chapman $\mathrm{S}$. Unravelling gossamer with boxing gloves problems in explaining the decline in smoking. $B M Y$ 1993;307:429-32.

10 Pope C, Mays N. Opening the black box: an encounter in the corridors of health services research. BMF 1993, 306:315-8.

11 Nouri FM, Lincoln NB. An extended activities of daily living index for stroke patients. Clinical Rehabilitation $1987 ; 1: 301-5$
12 Mahoney FI, Barthel DW. Functional evaluation: the Barthel index. Marrland State Medical foumal 1965; $14: 61-5$.

13 Hunt S.M McEwen J, McKenna SP. Miasuring health status. London: Croom Helm, 1986

14 Lum O, Brink TL, Yesavage JA. Heersetma P. Ade YM, Rose TL. Screening tests for geriatric depression. C/in (ivountol 1982;1:37-43.

15 Patton MQ. How to use qualitative methods in craluation. London: Sage Publications, 1987

10 Yesavage JA. Geriatric depression scale. Psichopharmacology Bulletin 1988;24:709-11.

17 Ebrahim S, Barer D, Nouri F. Use of the Nottingham Health Profile with patients after stroke. 7 Epidemiol Community Health 1986;40:166-9.

18 Hoffman JE. "Nothing can be done:" social dimensions of the treatment of stroke patients in a general hospital. Urban Life and Culture 1974;3(1):50-70.

19 Davis F. Passage through crisis. Indianapolis: Bobbs-Merrill, 1963.

20) Holbrook M. Stroke: social and emotional outcome. $7 R$ Coll Physicians Lond 1982;16:100 4

21 Williams R. A Protestant legaci: attitudes to death and illness amongst older Aberdonians. Oxford: Clarendon Press, 1990 .

22 Riley MW, Foner A, Waring J. Sociology of age. In: Smelser $\mathrm{NJ}$, ed. Handbook of Sociologi: Iondon: Sage, 1988:243-90

23 Cleary PD, MCNeil BJ. Patient satisfaction as an indicator of quality care. Inquiry 1988;25:25-36.

24 Fitzpatrick R. Satisfaction with health care. In: Fitzpatrick R, Hinton J, Newman S, Scambler E, Thompson J, eds. The experience of illness. London: Tavistock, 1984.

25 Hall JA, Dornan MC. What patients like about their medical care and how often they are asked: a metaanalysis of the satisfaction literature. Soc Sir Med $1988: 27: 935 \cdots 9$ 